\title{
Microfiltração do soro de leite de búfala utilizando membranas cerâmicas como alternativa ao processo de pasteurização
}

\author{
Microfiltration of whey from buffalo milk using ceramic \\ membranes as an alternative to the process of pasteurization
}

\author{
Hércules de Lucena LIRA ${ }^{1 *}$, Maria Cristina Delgado da SILVA ${ }^{1}$, \\ Maria Raphaella dos Santos VASCONCELOS ${ }^{1}$, Helio de Lucena LIRA², Ana Maria Queijeiro LOPEZ1,3
}

\section{Resumo}

O objetivo deste trabalho foi avaliar a eficiência de uma membrana cerâmica $(0,8 \mu \mathrm{m}$ de porosidade) na filtração de soro de leite de búfala (SLB) e comparar a qualidade microbiana e nutricional do filtrado com aquela do soro proveniente do processo de pasteurização $\left(65^{\circ} \mathrm{C}\right.$, 30 minutos). Foram realizadas sete repetições em que as amostras de SLB colhidas, antes e após a filtração (SF) ou pasteurização (SP), foram caracterizadas quanto ao $\mathrm{pH}$, densidade (d), acidez lática $\left({ }^{\circ} \mathrm{D}\right)$, umidade $(\mathrm{U})$, extrato seco total (EST), teor de gordura (TG), lactose (Lac) e proteínas (Pro), e também quanto ao número de bactérias aeróbias mesófilas. As amostras in natura de SLB apresentaram médias de $\mathrm{pH}=6,31$, acidez $=10,00, \mathrm{U}=89,60, \mathrm{EST}=10,40, \mathrm{~d}=1,027, \mathrm{P}=1,19 \%, \mathrm{Lac}=5,84 \%, \mathrm{e} \mathrm{G}=1,20 \%$. Os resultados indicaram que houve uma redução de carga microbiana média de 4,04 x log UFC. $\mathrm{mL}^{-1} \mathrm{em} \mathrm{AS}$ para 1,50 x log UFC.mL $\mathrm{mL}^{-1}$ nas amostras de SP e para 0,70 x log UFC.mL ${ }^{-1}$ nas amostras de SF. Portanto, a microfiltração por membrana cerâmica foi mais eficiente que o processo de pasteurização lenta em relação à redução de carga microbiana.

Palavras-chave: membrana cerâmica; leite de búfala; soro de leite; microfiltração.

\begin{abstract}
The purpose of this work was to evaluate the efficiency of a ceramic membrane with (porosity of $0.8 \mu \mathrm{m}$ ) to filter the whey of buffalo's milk aiming to reduce the microbial charge and characterize the nutritional value of this product. The results were compared with those of the pasteurization process $\left(65^{\circ} \mathrm{C}, 30\right.$ minutes). Seven assays were carried out by submitting the samples to filtration or pasteurization processes. The samples were then analyzed before (SBF) and after (SAF) filtration and after pasteurization (SAP) regarding the mesophyllic aerobic bacteria count. The milk whey samples before filtration (SBF) was also characterized regarding physico-chemical parameters (pH, density, acidity, humidity, total dried extract, concentration of total fats, lactose, and protein). The results indicate a reduction of the microbial charge from $4.04 \times$ log CFU.mL ${ }^{-1}$ to $1.50 \times \log$ CFU.mL ${ }^{-1}$ in the SAP samples and to $0.70 \times \log$ CFU. $\mathrm{mL}^{-1}$ in the SAF samples. Other findings were $\mathrm{pH}=6.29$, acidity $=10.07$, humidity $=89.94$, total dried extract $=10.06$, density $=1.029$, protein $=1.19 \%$, lactose $=5.85 \%$, and fat $=1.37 \%$. The microfiltration process using a ceramic membrane proved more efficient than the pasteurization process regarding microbial charge reduction.

Keywords: ceramic membrane; buffalo's milk; milk whey; microfiltration.
\end{abstract}

\section{Introdução}

Nos dias atuais, com o aumento da produção de queijos pelas indústrias de laticínios, torna-se necessário o melhor aproveitamento do subproduto desse processo, isto é, do soro líquido também conhecido como soro de queijo ou soro de leite. Este apresenta sabor ligeiramente ácido ou doce, e sua constituição depende da técnica de coagulação e fabricação do queijo (GIRALDO-ZUNIGA et al., 2004).

Durante muito tempo, este soro foi utilizado na alimentação animal ou descartado em corpos d'água, provocando a destruição da flora e da fauna devido ao seu alto valor de demanda bioquímica de oxigênio (DBO), que é cerca de
30000 a $50000 \mathrm{mg} \cdot \mathrm{L}^{-1}$. Tal índice é aproximadamente 100 vezes maior que o de um esgoto doméstico e, considerando uma produção média de $10000 \mathrm{~L}$ de soro por dia, esta teria o poder poluente equivalente ao de uma população de 5000 habitantes (GIROTO; PAWLOWSKI, 2001; MACHADO et al., 2001). Cada vez mais, portanto, a legislação ambiental exige das indústrias de laticínios um plano de tratamento ou reaproveitamento deste soro (BEM-HASSAN; GHALY, 1994). Acredita-se que aproximadamente $50 \%$ de todo o soro líquido produzido não é aproveitado, sendo este número ainda maior se forem consideradas as micro e pequenas empresas.

Recebido para publicação em 16/5/2007

Aceito para publicação em 5/1/2009 (002531)

Alimentos e Nutrição, Laboratório de Controle de Qualidade de Alimentos, Universidade Federal de Alagoas - UFAL, Faculdade de Nutrição, Av. Durval Melo Mota, s/n,

Campus Universitário, BR 104, Km 97, Tab. do Martins, CEP 57072-970, Maceió - AL, Brasil, E-mail: hercules@al.senai.br

2 Argilas e Materiais Cerâmicos, Universidade Federal de Campina Grande, Centro de Ciências e Tecnologia, Unidade Acadêmica de Engenharia de Materiais,

Rua Aprígio Veloso, 882, Bodocongó, CEP 59109-970, Campina Grande - PB, Brasil

3 Bioquímica do Parasitismo e Qualidade Química e Microbiológica de Alimentos - BPQQMA, Universidade Federal de Alagoas - UFAL,

Instituto de Química e Biotecnologia, Laboratório de Bioquímica do Parasitismo e Microbiologia Ambiental, Av. Durval Melo Mota, s/n, Campus Universitário,

BR 104, Km 97, Tabuleiro do Martins, CEP 57072-970, Maceió - AL, Brasil

${ }^{*}$ A quem a correspondência deve ser enviada 
Em função da tecnologia envolvida e do tipo de queijo produzido, o soro pode representar entre $80 \%$ e $95 \%$ do volume do leite utilizado no processo, apresentando $55 \%$ dos nutrientes originais deste. No Brasil, os queijos tiveram um consumo recorde nesta última década, consumo esse que continua em ascensão. Assim, uma vez que o tratamento de efluentes é dispendioso e, sendo o soro do leite rico em diversos nutrientes, pode ter sua utilização direta estimulada ou seus componentes aplicados em várias formulações de alimentos, como bebidas lácteas, leites fermentados, sucos, ricota, bebidas nutricionais fortificadas, etc. (DUMAIS et al., 1991; MORR; HA, 1993; CAYOT; LORIENT, 1997). Portanto, alternativas tecnológicas para o seu adequado aproveitamento são fundamentais (MULVIHILL, 1992; USDEC, 1997).

Os processos de separação e de utilização de membranas têm encontrado um campo vasto de aplicações, tanto nas indústrias químicas e farmacêuticas, como nas indústrias agroalimentares: desde a simples potabilidade da água a partir da água do mar, até o fracionamento, concentração e purificação de soluções moleculares (BRANS et al., 2004). Tais operações servem para concentrar ou fracionar o líquido, obtendo-se duas soluções de composição distintas, e baseiam-se na permeabilidade seletiva de um ou mais componentes através de membrana. As moléculas de tamanho inferior ao do poro da membrana passam através dela, enquanto as de tamanho superior ficam retidas pelo efeito peneira ou por forças repulsivas da superfície da membrana. A alimentação separa-se, portanto, em duas correntes: o fluido que atravessa a membrana, chamado de filtrado ou permeado e o que permanece ao lado da alimentação que contém os solutos ou sólidos suspensos que foram rechaçados pela membrana, chamado de concentrado ou retentado (GIRALDO-ZUNIGA et al., 2004; ORDÓNEZ, 2005a, 2005b).

O tratamento do soro é um dos processos da indústria de laticínios que mais utiliza membranas, sendo quatro delas amplamente usadas: a osmose reversa, a nanofiltração, a ultrafiltração e a microfiltração (ROSENBERG, 1995; CHEANG; ZYDNEY, 2003; 2004; MEHRA; DONNELLY, 1993; CADOTTE et al., 1988). Nessas indústrias, a membrana de filtração deve suportar altas vazões, possuir elevada seletividade e resistência (a bactérias e agentes químicos), possibilitando o trabalho com solventes, detergentes e desinfetantes. Apesar disso, a obstrução de seus poros (foulling) é um limitante de sua aplicação em certos processos industriais (ROSEMBERG, 1995; MAEDANI; MANSOURPANAH, 2004).

A separação de componentes do soro utilizando membranas cerâmicas pode levar não só à produção de constituintes com elevado grau de pureza mas também à obtenção de produtos comercialmente esterilizados e com aplicação na fabricação de novos derivados lácteos. Vários pesquisadores, portanto, têm utilizado a microfiltração por membranas cerâmicas com o fim de separar e fracionar lipídios do leite integral, remover bactérias e esporos em leite desnatado, concentrar micelas de caseína de leite desnatado e recuperar proteínas de soro de leite (BRANS, 2004; HANEMAAIJER, 1985; XU et al., 2000).

Em Alagoas, em termos de características estruturais e tecnológicas, há diversos sistemas de produção, com diferentes níveis tecnológicos. As miniusinas e fabriquetas artesanais, apesar de apresentarem um nível tecnológico inferior, têm disputado "competitivamente" o mercado local com mercadorias similares às de grandes laticínios. Entretanto, a diversificação é baixa e o mercado bastante restrito a queijos de coalho e manteiga e, consequentemente, um volume alto de soro de leite é produzido e desperdiçado.

Em se tratando de queijo tipo coalho produzido a partir de leite de búfala, Alagoas possui uma empresa que faz parte da Incubadora de Laticínios do Estado. O propósito do presente trabalho, portanto, foi caracterizar em termos físico-químicos o soro de leite de búfala in natura produzido nessa empresa e avaliar a efetividade do uso de uma membrana cerâmica tubular de alumina, confeccionada no Laboratório de Membranas Cerâmicas (LMC) do Departamento de Materiais (DEMA), do Centro de Ciências e Tecnologia (CCT), da Universidade Federal de Campina Grande (UFCG), na microfiltração mesmo, como alternativa ao processo de pasteurização, viabilizando assegurar a qualidade, a segurança e o aproveitamento deste produto.

\section{Material e métodos}

\subsection{Amostras de soro de leite}

O leite de búfala in natura utilizado nos experimentos foi doado pelo Laticínio Búfalo Bill, situado a $60 \mathrm{Km}$ de Maceió, em São Luiz do Quitunde - AL. Foram realizados sete ensaios, utilizando amostras com $5 \mathrm{~L}$ desse leite resfriado, o qual foi transportado em isopor com gelo para o Laboratório de Microbiologia de Alimentos (LMA) da Faculdade de Nutrição (FANUT)- UFAL.

Considerando-se a necessidade de se uniformizar as condições nas quais o soro fosse obtido, o processamento do queijo coalho foi realizado no LMA-FANUT/UFAL, de acordo com o fluxograma apresentado na Figura 1.

Após sua recepção no laboratório, o leite cru foi pasteurizado em banho-maria à temperatura de $65^{\circ} \mathrm{C}$ por 30 minutos e resfriado à temperatura de $35^{\circ} \mathrm{C}$. Em seguida, adicionou-se o cloreto de cálcio e o coalho, e a massa permaneceu em repouso por 45 minutos para coagulação. Logo após, realizou-se o corte da coalhada e a agitação da massa para a obtenção de soro através da dessoragem (Figura 1).

\subsection{Processo de microfiltração e pasteurização do soro de leite}

O módulo experimental de membrana cerâmica tubular de alumina (com 10\% de argila esmectítica verde, porosidade de cerca de $0,8 \mu \mathrm{m}$ ), em área com aproximadamente $0,000436 \mathrm{~m}^{2}$, foi caracterizado por Lira (2005) e cedido pelo LMC-DEMA/ UFCG, sendo utilizado no processo de microfiltração do soro de leite.

A partir das amostras de soro (SA) obtidas da fabricação de queijo coalho e submetidas a análises físico-químicas, colheramse alíquotas para sua submissão ao processo de microfiltração (SF) e para o processo de pasteurização lenta (SP) a $65^{\circ} \mathrm{C}$ por 30 minutos, sendo estas posteriormente analisadas quanto à sua carga microbiológica. 
A microfiltração foi realizada à temperatura ambiente $\left(28 \pm 1{ }^{\circ} \mathrm{C}\right)$ e à pressão de 0,5 bar, empregando-se uma bomba de marca KNF FLODOS, modelo END 300 TT.18.

\subsection{Análises}

\section{Análises físico-químicas}

Os parâmetros físico-químicos avaliados foram: $\mathrm{pH}$, acidez titulável, umidade e proteína, conforme metodologia descrita no manual do Instituto Adolfo Lutz (2005). As análises de densidade, gordura, lactose e extrato seco total (EST) foram realizados em triplicata, conforme recomendado para o leite, e segundo os métodos analíticos oficiais físico-químicos para controle de leite e produtos lácteos definidos pelo Ministério da Agricultura (BRASIL, 2006). As medidas dos valores de $\mathrm{pH}$ foram realizadas em potenciômetro digital, e as determinações dos teores de acidez, através da titulação ácido-alcalimétrica, usando-se a fenoftaleína como indicador. As determinações de umidade por secagem da amostra foram realizadas em estufa a $105^{\circ} \mathrm{C}$. O teor de gordura foi obtido utilizando-se o método de Gerber, e o extrato seco total foi mensurado pela diferença de umidade. Para o teor de proteínas totais, foi utilizado o método de Kjeldahl e a concentração de equivalentes de lactose foi mensurada conforme a análise de glicídios redutores totais (BRASIL, 2006).

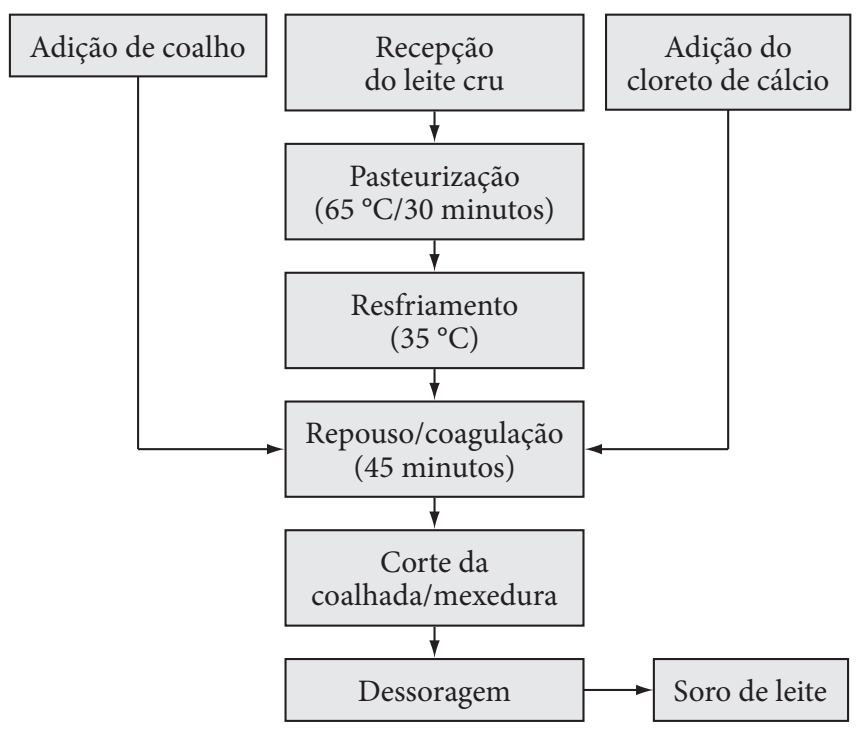

Figura 1. Fluxograma de obtenção do soro de leite a partir da produção de queijo coalho.

\section{Análise microbiológica}

As amostras foram submetidas ao método 990.12 recomendado pela AOAC (2000) para contagem total de bactérias aeróbias mesófilas, em superfície Petrifilm (duas por amostra), inoculada com 1,0 mL de determinada diluição das amostras, conforme instruções do fabricante. Em seguida, o material foi incubado a $35^{\circ} \mathrm{C} \pm 1{ }^{\circ} \mathrm{C}$ por $48 \pm 2$ horas. Colônias vermelhas foram contadas como bactérias aeróbias mesófilas em contador de colônias e os resultados expressos em log 10 unidades formadoras de colônias (UFC) por $\mathrm{mL}$ de soro de leite.

\section{Análises estatísticas}

Os dados das análises microbiológicas foram submetidos ao procedimento ANOVA, usando-se o programa Microsoft Excell versão 2000, com aplicação do teste $F$. Quando o teste $F$ foi significativo ao nível de $5 \%$, a análise estatística teve continuidade, aplicando-se o Teste de comparação múltipla de médias de Tukey (FERREIRA, 2000). Para os testes de aceitação, o delineamento foi realizado com base no modelo do delineamento inteiramente casualizado (DIC), no qual foram considerados os princípios da casualidade e da repetição, com três tratamentos (SA, SF, SP).

\section{Resultados e discussão}

A caracterização físico-química do soro de leite de búfala in natura, filtrado ou pasteurizado é apresentada na Tabela 1. Observaram-se valores médios de umidade $(89,60 \%)$ e proteína $(1,19 \%)$ inferiores aos obtidos por Florentino et al. (2005) em amostras de soro resultante da produção de queijo coalho de leite de vaca em seis queijarias do Rio Grande do Norte, que foram de $92,36 \%$ e $1,78 \%$, respectivamente. Já os valores médios de extrato seco total $(10,40 \%)$ e lactose $(5,84 \%)$ estão acima dos encontrados nas amostras estudadas por Florentino et al. (2005), que foram respectivamente de 7,64 e 4,20\%. Os valores e $\mathrm{pH}$, densidade e acidez foram semelhantes aos detectados por Morr (1990) e Carvalho (2006), em estudos de amostras de soro de queijos de leite de vaca no Brasil, em que estes foram, respectivamente, 6,1-6,5 (pH), 1,027-1,030 (d) e 10,98 ( $\left.{ }^{\circ} \mathrm{D}\right)$

Santos e Ferreira (2001) caracterizaram o soro de leite de vaca com $6,90 \%$ de extrato seco total; $0,30 \%$ de gordura; $0,90 \%$ de proteínas; e 5,00\% de lactose, enquanto Farro (2003), em estudo realizado com soro de leite de vaca, obtido da produção de queijo minas frescal, detectou $6,13-6,72 \%$ de extrato seco total; $0,62-0,77 \%$ de proteína total; $0,62-0,71 \%$ de gordura; e $4,23-4,76 \%$ de lactose. Spadoti et al. (2003), analisando soro de leite de vaca obtido da fabricação de queijo prato sem tratamento

Tabela 1. Média dos resultados das análises físico-químicas de amostras de soro de leite de búfala obtido da produção de queijo de coalho, e filtradas ou pasteurizadas.

\begin{tabular}{lccccrcrc}
\hline $\begin{array}{c}\text { Amostras de soro de } \\
\text { leite de búfala }\end{array}$ & $\begin{array}{c}\text { Densidade } \\
\left(15^{\circ} \mathrm{C}\right)\end{array}$ & $\mathrm{pH}$ & Acidez lática $\left({ }^{\circ} \mathrm{D}\right)$ & Umidade (\%) & EST (\%) & Gordura (\%) & Proteína (\%) & Lactose (\%) \\
\hline in natura (SA) & $1,027^{\mathrm{a}}$ & $6,31^{\mathrm{a}}$ & $10,00^{\mathrm{a}}$ & $89,60^{\mathrm{a}}$ & $10,40^{\mathrm{a}}$ & $1,20^{\mathrm{a}}$ & $1,19^{\mathrm{a}}$ & $5,84^{\mathrm{a}}$ \\
pasteurizado (SP) & $1,026^{\mathrm{a}}$ & $6,51^{\mathrm{ab}}$ & $9,16^{\mathrm{b}}$ & $90,93^{\mathrm{a}}$ & $9,40^{\mathrm{b}}$ & $1,16^{\mathrm{a}}$ & $1,14^{\mathrm{a}}$ & $5,74^{\mathrm{a}}$ \\
filtrado (SF) & $1,025^{\mathrm{a}}$ & $6,58^{\mathrm{b}}$ & $8,50^{\mathrm{c}}$ & $93,13^{\mathrm{a}}$ & $9,07^{\mathrm{c}}$ & $0,07^{\mathrm{c}}$ & $0,91^{\mathrm{a}}$ & $5,04^{\mathrm{b}}$ \\
\hline
\end{tabular}

${ }^{\star}$ Letras iguais em uma mesma coluna indicam que não há diferença significativa ao nível de $5 \%(\mathrm{p} \leq 0,05)$ entre as amostras; e EST = extrato seco total. 
térmico, detectaram uma concentração protéica de 0,98\%. Estes valores estão abaixo dos detectados no soro de leite de búfala aqui estudado, o que demonstra o elevado valor nutricional deste produto.

Embora tenha havido uma perda de cerca de $94 \%$ de lipídios totais, $23,5 \%$ de proteínas, $13,7 \%$ de lactose, $12,8 \%$ de extrato seco total e $15 \%$ de acidez lática durante o processo de filtração, a pasteurização também levou à redução de cerca de 3,3\% de lipídios totais, 4,2\% de proteínas (apesar da desnaturação prevista para o restante), $1,7 \%$ de lactose, $9,6 \%$ de extrato seco total e $8,4 \%$ de acidez lática das amostras. É provável que a incrustação da membrana, em face da retenção de microrganismos, micelas de gorduras e grandes moléculas de proteínas, tenha reduzido a acidez lática, do soro filtrado, o que é uma vantagem aliada ao processo de retenção de gorduras, que, em geral, são as moléculas menos desejadas do ponto de vista nutracêutico do produto alimentício. Porém, um aprimoramento do sistema, utilizandose previamente uma membrana com porosidade ligeiramente superior e que permita a separação parcial de lipídios, poderá aumentar seu fluxo/vazão e reduzir a incrustação de proteínas na membrana de $0,8 \mu \mathrm{m}$.

Quanto às análises microbiológicas realizadas (Tabela 2), verificou-se que o número médio de bactérias aeróbias mesófilos do soro não tratado diferiu significativamente $(\mathrm{p} \geq 0,05)$ daqueles do soro pasteurizado e do soro filtrado (Tabela 2). Portanto, tanto a microfiltração como a pasteurização diminuem sensivelmente a carga microbiana do solo in natura, porém a microfiltração apresenta-se mais eficiente, visto que reduziu em cerca de $82 \%$ o número de bactérias aeróbias mesófilas, isto é, de 4,04 x log UFC. $\mathrm{mL}^{-1}$ para $0,72 \times \log \mathrm{UFC} . \mathrm{mL}^{-1}$, corroborando dados de Rektor e Vatai (2004), os quais verificaram que soro de queijo muçarela de leite de vaca filtrado em membrana cerâmica de 0,2 $\mu \mathrm{m}$ apresentou seu número de células de Lactobacillaceae reduzido em $100 \%$. A pasteurização reduziu esse parâmetro em apenas $62 \%$. Esses dados confirmam os de perda de acidez lática entre as amostras, uma vez que a maior retenção de bactérias pela membrana cerâmica levou também a uma menor produção desse ácido.

Brans et al. (2004) apontaram que, para a microbiota natural do leite, o tamanho das bactérias predominantes está entre 0,4-2,0 $\mu \mathrm{m}$, daí a importância do uso de membranas com porosidades inferiores (máximo de $0,4 \mu \mathrm{m}$ ). No presente estudo, a redução de cerca de $82 \%$ da carga microbiana estudada permite avaliar a porosidade de $0,8 \mu \mathrm{m}$ como satisfatória, visto que não

Tabela 2. Média da contagem de bactérias aeróbias mesófilas viáveis em amostras de soro de leite de búfala antes e após a filtração ou a pasteurização.

\begin{tabular}{lcc}
\hline \multirow{2}{*}{$\begin{array}{c}\text { Amostras de soro de } \\
\text { leite de búfala }\end{array}$} & \multicolumn{2}{c}{ Aeróbias mesófilas } \\
\cline { 2 - 3 } & Média de UFC.mL $\mathrm{mL}^{-1}$ & $\log 10$ de UFC.mL $\mathrm{mL}^{-1}$ \\
\hline in natura (SA) & $1,80 \times 10^{4}$ & $4,04^{\mathrm{a}}$ \\
pasteurizado (SP) & $3,43 \times 10^{1}$ & $1,50^{\mathrm{b}}$ \\
filtrado (SF) & $5,36 \times 10^{0}$ & $0,72^{\mathrm{c}}$ \\
\hline
\end{tabular}

${ }^{*}$ Letras iguais em uma mesma coluna indicam que não há diferença significativa ao nível de $5 \%(p \leq 0,05)$ entre as amostras. alterou a natureza ou estado de agregação dos nutrientes do soro, como ocorre com o tratamento térmico (ROSENBERG, 1995; KINSELLA; WHITEHEAD, 1989; HANEMAAIJER, 1985), que reduziu a acidez lática e praticamente todo o conteúdo de lipídios, e as perdas em proteínas podem ser reduzidas se o sistema for acoplado a outra membrana de maior porosidade.

\section{Conclusões}

O soro de leite de búfala apresentou teores médios de proteína, gordura e lactose acima das médias obtidas para o soro de leite de vaca, registradas na literatura; revelando o grande desperdício nutricional em função do descarte corrente desse produto no meio ambiente;

A utilização do processo de microfiltração por membrana cerâmica de alumina (porosidade de cerca de $0,8 \mu \mathrm{m}$ ) foi mais eficiente que o processo de pasteurização tradicional do soro de leite, visto reduzir a carga microbiana de 4,04 x log UFC. $\mathrm{mL}^{-1}$ para $0,72 \times \log$ UFC.mL $L^{-1}$, enquanto, no soro pasteurizado, esta foi de $1,50 \times \log$ UFC.mL $L^{-1}$. Tal processo é uma alternativa viável para aumentar a vida útil do soro de leite de búfala, ideal para fabricação de vários derivados na indústria de laticínios.

\section{Agradecimentos}

Ao Laticínio Búfalo Bill, pela doação das amostras de leite de búfala, à FINEP/FAPEAL, pelo auxílio à pesquisa, e ao PIBIC-CNPq e FAPEAL pelas bolsas de iniciação científica concedidas sequencialmente à terceira coautora.

\section{Referências bibliográficas}

Association of Official Agricultural Chemists - AOAC. Method 990.12: Official methods of analysis of AOAC International. $17 \mathrm{ed}$. Gaithersburg: AOAC International, 2000. p. 22-23.

BEM-HASSAN, R. M.; GHALY, A. E. Contonuous propagation of Kluyveromyces fragilis in cheese whey for pollution potencial reduction. Applied Biochemistry and Biotechnology, v. 47, p. 89-105, 1994.

BRANS, G. et al. Membrane fractionation of milk: state of the art and challenges. Journal of Membrane Science, v. 243, n. 2, p. 263-272, 2004.

BRASIL. Ministério da Agricultura, Pecuária e Abastecimento. Instrução Normativa $\mathrm{n}^{\circ}$ 68, de 12 de Dezembro de 2006. Métodos analíticos oficiais físico-químicos para controle de leite e produtos lácteos (revoga Instrução Normativa $\mathrm{n}^{\circ} 22$, de 14 de Abril de 2003). Diário Oficial da União, Brasília, 14 de Dezembro 2006, Seção 1, Página 8, 2006.

CADOTTE, J. et al. Nanofiltration membranes broaden the use of membrane separation technology. Desalination, v. 70, n.1, p. 77-88, 1988.

CARVAlHO, B. M. A. et al. Caracterização fisico-quimica e propriedades termofisicas de soro de queijo obtido de leite de cabra. Revista do Instituto de Laticínios do Cândido Tostes, v. 61, p. 287-290, 2006.

CAYOT, P.; LORIENT, D. Structure-function relationships of whey proteins. In: DAMODARAN, S.; PARAF, A. Food proteins and their applications. New York: Marcel Dekker Inc., 1997. p. 225-255. 
CHEANG, B.; ZYDNEY, A. L. A. A two-stage ultrafiltration process for fractionation of whey protein isolate. Journal of Membrane Science, v. 231, n. 1, p. 159-167, 2004.

CHEANG, B.; ZYDNEY, A. L. Separation of alpha-lactalbumin and beta-lactoglobulim using membrane ultrafiltration. Biotechnology and Bioengineering, v. 83, n. 2, p. 201-209, 2003.

DUMAIS, R.; BLAIS, J.; CONRAD, F. Queso. In: AMIOT, J. Ciência y tecnologia de la leche. Zaragoza- Espana: Ed. Acribia S.A., 1991. p. 249-296.

FARRO, P. C. A. Ultrafiltração do soro de queijo minas frescal prétratado e microfiltrado: Efeitos da vazão volumétrica e da pressão transmembrana no fluxo de permeado. Campinas, 2003. 208 p. Dissertação (Mestrado em Ciência e Tecnologia de Alimentos) Universidade Estadual de Campinas-UNICAMP.

FERREIRA, P. V. Estatística experimental aplicada à agronomia. Maceió: Edufal - Editora da Universidade Federal de Alagoas, $2000.87 \mathrm{p}$.

FLORENTINO, E. R. et al. Caracterização do soro de queijo visando processo de aproveitamento. Revista Higiene Alimentar, v. 19, n. 130, p. 30-32, 2005.

GIRALDO-ZUNIGA, A. D. et al. Tecnologias aplicadas ao processamento do soro de queijo. Revista do Instituto de Laticínios Cândido Tostes, v. 59, n. 340-341, p. 53-66, 2004.

GIROTO, J. M.; PAWLOSWSKY, U. O soro do leite e as alternativas para seu beneficiamento. Brasil Alimentos, Setembro/Outubro, p. 43-46, 2001.

HANEMAAIJER, J. H. Microfiltration in whey processing. Desalination, v. 53, n. 1, p. 143-155, 1985.

INSTITUTO ADOLFO LUTZ. Métodos químicos e físicos para análise de alimentos. 4 ed. Brasília, 2005. p. 97-99.

KINSELLA, J. E.; WHITEHEAD, D. M. Proteins in whey: chemical, physical and functional properties. In: Kinsella, J. E. (Eds.). Advances in Food and Nutrition Research. San Diego: Elsevier Publisher, 1989. v. 33, p. 343-438.

LIRA, A. L. Processamento de água de coco verde (Cocos nucifera) por microfiltração com membrana cerâmica. Paraíba, 2005. 89p. Dissertação (Mestrado em Ciência e Tecnologia de Alimentos) Universidade Federal da Paraíba.
MACHADO, R. M. G.; SILVA, P. C.; FREIRE, V. H. Controle Ambiental em indústrias de laticínios. Brasil Alimentos, Março/Abril, p. 34-36, 2001.

MAEDANI, S. S.; MANSOURPANAH, Y. Chemical cleaning of reverse osmosis membranes fouled by whey. Desalination, v. 161, n. 1, p. 13-24, 2004.

MEHRA, R. K.; DONNELLY, W. Fractionation of whey protein components trough a large pore size hydrophilic, cellulose membrane. Journal of Dairy Research, v. 60, n.1, p. 89-97, 1993.

MORR, C. V.; HA, E. W. Whey protein concentrates and isolates processing and functional properties critical reviews. Critical Reviews in Food Science and Nutrition, v. 33, n. 6, p. 413-476, 1993.

MOOR, C. V. Effect of heating and elevated temperature storage on cheese whey. Journal of Food Science, v. 55, n. 4, p. 1177-1179, 1990.

MULVIHILL, D. M. Production, functional properties and utilization of milk protein products. In: Fox, P. F. Advanced dairy chemistry: Proteins. London: Elsevier Applied Science, 1992. vol. 1, p. 369-404.

ORDÓNEZ, J. A. Tecnología de alimentos: Componentes dos alimentos e processos. Porto Alegre: Artmed Editora, 2005a.

ORDÓNEZ, J. A. Tecnología de alimentos: Alimentos de origem animal. Porto Alegre: Artmed Editora, 2005b.

REKTOR, A.; VATAI, G. Membrane filtration of mozzarella whey. Desalination, v. 162, n. 2, p. 279-286, 2004.

ROSEMBERG, M. Current and future applications for membrane processes in the dairy industry. Trends in Food Science and Technology, v. 6, n. 1, p. 12 -16, 1995.

SANTOS, J. P. V.; FERREIRA, C. L. L. F. Alternativas para o aprovetamento de soro de queijo nos pequenos e médios laticínios. Revista do Instituto de Laticínios Cândido Tostes, v. 56, n. 321, p. 44-50, 2001.

SPADOTI, L. M. et al. Avaliação do rendimento do queijo tipo prato obtido por modificações no processo tradicional de fabricação. Ciência e Tecnologia de Alimentos, v. 23, n. 3, p. 492-499, 2003.

U. S. Dairy Export Council - USDEC. Manual de referência para produtos de soro dos Estados Unidos. Arlington: USDEC News, 1997. $135 \mathrm{p}$.

XU, Y. et al. Separation of bovine immunoglobulin $G$ and glycomacropeptide from dairy whey. Process Biochemistry, v. 36, n. 5, p. 393-399, 2000. 